\title{
Changes of Left Ventricular Systolic Function in Patients Undergoing Coronary Artery Bypass Grafting
}

\author{
Vasil Papestiev ${ }^{{ }^{*}}$, Sasko Jovev ${ }^{1}$, Marjan Sokarovski ${ }^{1}$, Petar Risteski ${ }^{1,2}$, Valentina Andova ${ }^{3}$, Vangel Zdraveski ${ }^{1}$, Kujtim \\ Dzeljilji ${ }^{1}$, Sonja Grazhdani ${ }^{1}$, Ljubica Georgievska-Ismail ${ }^{3}$ \\ ${ }^{1}$ University Clinic for Cardiac Surgery, Medical Faculty, Ss. Cyril and Methodius University of Skopje, Skopje, Republic of \\ Macedonia; ${ }^{2}$ Department of Thoracic and Cardiovascular Surgery, Johann Wolfgang Goethe University, Frankfurt, Germany; \\ ${ }^{3}$ University Clinic of Cardiology, Medical Faculty, Ss. Cyril and Methodius University of Skopje, Skopje, Republic of \\ Macedonia
}

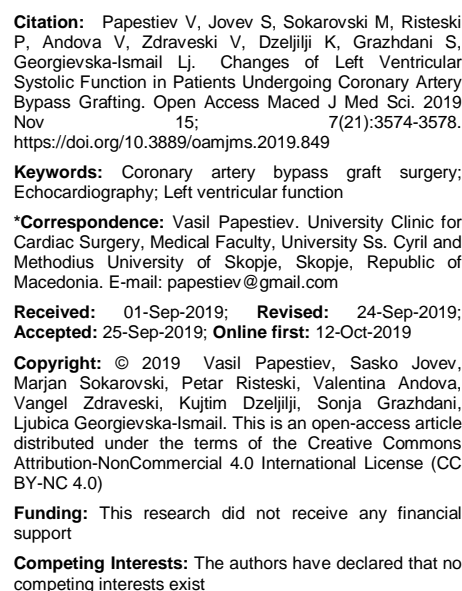

Competing Interests:
competing interests exist

\begin{abstract}
AIM: This prospective study was designed to evaluate the changes in left ventricular (LV) systolic function after coronary artery bypass grafting (CABG) in patients with both normal and abnormal pre-operative systolic function.

METHODS: During the period from October 2017 to October 2018, forty-seven consecutive patients undergoing CABG were enrolled in this prospective study. Transthoracic echocardiography was performed within 1 week before CABG as well as 4 to 6 months after surgery. All measurements were made by a single experienced investigator.

RESULTS: While the mean LV ejection fraction (LVEF) showed neither improvement nor significant reduction in the whole group of patients following CABG (from $54.21 \pm 15.36$ to $53.66 \pm 11.56 \%, p=0.677$ ), significant improvement in LVEF was detected in the subgroup of patients with pre-operative LV dysfunction (from $40.05 \pm$ 8.65 to $45.85 \pm 9.04 \%, p=0.008)$. On the other hand, there was a significant decline in LEFT in the subgroup of patients with normal pre-operative LEFT (from $64.70 \pm 9.72$ to $59.44 \pm 9.75 \%, p=0.008$ ). As for the other parameters of systolic function, significant decrease in LV end-diastolic volume index (LVEDVI) ( $P=0.001)$, LV end-systolic volume index (LVESVI) $(p=0.0001)$, wall motion score index (WMSI) $(p=0.013)$ and LVmass index in male patients $(p=0.011)$ was shown only in patients with decreased LVEF after CABG. Patients with improved postoperative LVEF $(53.2 \%$ of all patients) had significantly lower baseline LVEF $(p=0.0001)$, higher LVESVI (0.009) and higher WMSI $(p=0.006)$ vs patients with worsened postoperative LVEF $(38.3 \%$ of all patients). Postoperative improvement of LVEF was correlated with stabile angina, lack of preoperative myocardial infarction and smoking, higher baseline WMSI, higher LV internal diameters and indexed volumes in diastole and systole and lower baseline LVEF. In stepwise linear regression analysis the value of baseline LVEF appeared as independent predictor of improved LVEF after CABG ( $\mathrm{B}=0,836 \% ; 95 \% \mathrm{Cl} 0.655-1.017 ; \mathrm{p}=0.0001)$.

CONCLUSION: Our study showed that LVEF, internal baseline diameters and indexed volumes of LV in diastole and systole are important determinants of postoperative change in LVEF. In patients with preoperative depressed myocardial function, there is an improvement in systolic function, whereas in patients with preserved preoperative myocardial function, the decline in postoperative LVEF was detected.
\end{abstract}

\section{Introduction}

Patients with multivessel coronary artery disease (CAD), especially those with stenosis of the left main (LM) coronary artery and suitable coronary anatomy benefit from coronary artery bypass grafting (CABG) [1], [2], [3]. The goal of CABG is not only to allay symptoms and improve survival [4] but also to optimise cardiovascular function and prevent progressive remodelling. Coronary artery disease (CAD) lead's to left ventricular (LV) dysfunction as a result of myocardial scarring, stunning, or hibernation [5]. The impact of CABG on regional and global LV systolic function has been studied but with conflicting results, most probably because of patient selection. Most of the studies that evaluated the effect of CABG in patients with severe LV dysfunction showed significant improvement in LV ejection fraction (LVEF) and LV systolic parameters after revascularisation [3], [6], [7].

Moreover, those patients with ischemic symptoms and the most severe LV dysfunction appear to benefit most from surgical revascularisation. On the other hand, only a few retrospective studies evaluate the changes in LV systolic function after CABG in patients with preserved baseline LVEF. In these patients despite the apparent improvement in 
cardiac function conventional echocardiography did not change significantly even showed a decline in baseline LVEF [8], [9]. Despite advances in cardiac imaging, we believe that 2-dimensional (2D) echocardiography is still most suitable for detection of myocardial function recovery after CABG to highlight the controversies. This prospective study was designed to evaluate the changes in LV systolic parameters after CABG in patients with both normal and abnormal pre-operative systolic function.

\section{Methods}

\section{Study patients}

During the period from October 2017 to October 2018, forty-seven consecutive patients undergoing $\mathrm{CABG}$ were enrolled in this prospective study. All procedures were done on-pump with cardiopulmonary bypass (CPB). In every case, the left internal thoracic artery (LITA) was used to bypass the left anterior descending artery (LAD). None of the patients had associated surgical procedures such as valve replacement or surgery of the ascending aorta. This study was approved by the Medical Ethics Committee of Medical School, University Ss. "Cyril and Methodius", Skopje, and all patients provided informed consent.

\section{2-D Echocardiography parameters}

Transthoracic echocardiography was performed within 1 week before CABG as well as 4 to 6 months after surgery. All measurements were made by a single experienced investigator. Standard assessments of LV dimensions, wall thickness, LV mass, LV volumes as well as LV systolic function were performed in standard views using 2D echocardiography and Tissue Doppler imaging (TDI) on commercially available equipment (Vivid 7; GE, USA) according to the professional association recommendations [10].

\section{Statistical analysis}

Categorical parameters were summarised as percentages and continuous parameters as mean \pm SD. Comparisons of preoperative vs postoperative data were performed using a Wilcoxon Signed Rank test for related samples. Continuous variables were compared using the nonparametric Mann-Whitney test for independent samples and categorical parameters were compared using Pearson's chi-square test. Assessment of correlations was done using Pearson's correlation analysis. Stepwise regression analysis was performed to define the independent significant predictive variable of postoperative LV ejection fraction. All data analysis was performed using SPSS version 25.0 (IBM SPSS, Inc., Chicago, Illinois), and $p$-value $\leq 0.05$ was considered significant.

\section{Results}

\section{Patient characteristics}

The patients were divided into two subgroups: those with normal preoperative LVEF (LVEF > 50\% n $=27$ ) and those with abnormal LVEF (LVEF $\leq 50 \% \mathrm{n}$ $=20$ ). The baseline demographic and clinical characteristics of the patients as a whole and divided in subgroups, including coronary anatomy, and the postoperative course are shown in Table 1 and were similar in both subgroups.

Forty-three percent of patients had decreased LVEF $(\leq 50 \%)$ at baseline. These patients had significantly lower body mass index, higher Euro SCORE 2 and more likely to have chronic kidney disease. There was no statistically significant difference in age, gender, prior myocardial infarction, SINTAX score and other comorbidities between the groups. Distribution of 3-vessel CAD and significant LM stenosis was also similar between the two groups. The number of bypassed vessels was not significantly different between the subgroup of patients with normal, and abnormal LVEF. The majority of patients received three bypass grafts (median 3 , range $2-5$ ), and in all patient, a left internal thoracic artery to the left anterior descending coronary artery bypass graft was used (Table 1).

Table 1: Baseline characteristics in the study population as a whole and comparison of demographic, clinical and operative characteristics of 47 patients divided according to the preoperative LVEF

\begin{tabular}{|c|c|c|c|c|}
\hline Parameter & $\begin{array}{c}\text { All patients } \\
N=47\end{array}$ & $\begin{array}{c}\text { LEFT }>50 \% \\
\mathrm{~N}=27\end{array}$ & $\begin{array}{c}\text { LVEF } \leq 50 \% \\
N=20\end{array}$ & $\mathrm{p}$ \\
\hline Age (years) & $65.55 \pm 8.25$ & $64.93 \pm 7.74$ & $66.40 \pm 9.02$ & 0.628 \\
\hline \multicolumn{5}{|l|}{ Gender ( $n / \%)$} \\
\hline Male & $35 / 74.5$ & $18 / 66.7$ & $17 / 85.0$ & 0.154 \\
\hline $\begin{array}{c}\text { Female } \\
\text { BMI (kg/m2) }\end{array}$ & $\begin{array}{c}12 / 25.5 \\
27.40 \pm 4.38\end{array}$ & $\begin{array}{c}9 / 33.3 \\
28.99+4.68\end{array}$ & $\begin{array}{c}3 / 15 \\
2525+286\end{array}$ & 0,004 \\
\hline Euro SCORE & $2.17 \pm 0.60$ & $1.66 \pm 0.91$ & $\begin{array}{l}25.250 .06 \\
2.61 \pm 1.97\end{array}$ & 0.058 \\
\hline Angina, stable (n/\%) & $26 / 55.3$ & $18 / 66.7$ & $8 / 40$ & 0.064 \\
\hline $\begin{array}{l}\text { Previous MI }(\mathrm{n} / \%) \\
\text { Prof }\end{array}$ & $25 / 53.2$ & $12 / 44.4$ & $13 / 65.0$ & 0.135 \\
\hline Previous PCl (n/\%) & $15 / 31.9$ & $7 / 25.0$ & $8 / 40.0$ & 0.306 \\
\hline Urgent CABG (n/\%) & $14 / 29.8$ & $9 / 33.3$ & $5 / 25.0$ & 0.748 \\
\hline Preoperative AF (n/\%) & $2 / 4.3$ & $1 / 3.7$ & $1 / 5.0$ & 0.828 \\
\hline $\operatorname{COPD}(n / \%)$ & $8 / 17.0$ & $4 / 14.8$ & $4 / 20.0$ & 0.640 \\
\hline PVD (n/\%) & $6 / 12.8$ & $2 / 7.4$ & $4 / 20.0$ & 0.201 \\
\hline CKD $(n / \%)$ & $9 / 19.1$ & $2 / 7.4$ & $7 / 35$ & 0.017 \\
\hline Smoking $(n / \%)$ & $17 / 36.2$ & $7 / 25.9$ & $10 / 50,0$ & 0.089 \\
\hline Hypertension (n/\%) & $47 / 100$ & $27 / 100$ & $20 / 100$ & \\
\hline Dyslipidemia (n/\%) & $46 / 97.9$ & $26 / 96.3$ & $20 / 100$ & 0.384 \\
\hline Diabetes mellitus (n/\%) & $23 / 48.9$ & $13 / 48.1$ & $10 / 50.0$ & 0.900 \\
\hline $\begin{array}{l}\text { SYNTAX score } \\
\text { SYllof }\end{array}$ & $31.53 \pm 6.58$ & $31.48 \pm 5.99$ & $31.60 \pm 7.46$ & 0.612 \\
\hline Left main disease & $19 / 40.4$ & $11 / 40,7$ & $8 / 40.0$ & 0.599 \\
\hline LAD proximal disease & $38 / 80.9$ & $20 / 74.1$ & $18 / 90.0$ & 0.170 \\
\hline 1 vessel disease & & & & - \\
\hline 2 vessel disease & $9 / 19.1$ & $6 / 22.2$ & $\begin{array}{l}3 / 15.0 \\
17 / 850\end{array}$ & 0.407 \\
\hline 3 vessel disease & $38 / 80.9$ & $21 / 77.8$ & $17 / 85.0$ & 0.407 \\
\hline Number of grafts & $2.77 \pm 0.72$ & $2.85 \pm 0.77$ & $2.65 \pm 0.67$ & 0.523 \\
\hline \multicolumn{5}{|l|}{$\begin{array}{l}\text { Number of grafts per } \\
\text { patient }(n / \%)\end{array}$} \\
\hline 1 & $1 / 1.2$ & - & $1 / 5.0$ & \\
\hline 2 & $15 / 31.9$ & $9 / 33.3$ & $6 / 30.0$ & \\
\hline 3 & $26 / 55.3$ & $14 / 51.9$ & $12 / 60.0$ & \\
\hline 4 & $4 / 8.5$ & $3 / 11.1$ & $1 / 5.0$ & 0.597 \\
\hline 5 & $1 / 1.2$ & $1 / 3.7$ & & \\
\hline CPB time (min) & $108.91 \pm 29.73$ & $108.37 \pm 28.37$ & $109.65 \pm 32.20$ & 0.763 \\
\hline Ischemic time (min) & $66.09 \pm 20.03$ & $65.52 \pm 18.92$ & $66.85 \pm 21.92$ & 0.698 \\
\hline
\end{tabular}




\section{Left ventricular myocardial function before and after CABG}

Echocardiographic systolic parameters in the study group as a whole and in the subgroups of patients with normal and decreased LVEF before and after CABG are shown in Table 2.

In the study group as a whole there was statistically significant reduction in LVEDVI $(p=0.001)$, LVESVI $(p=0.003)$, IVSd $(p=0.037)$ and WMSI $(p=$ $0.016)$. There was a significant improvement in MAPSE $(p=0.001)$. Mean LVEF showed neither improvement nor significant reduction in the whole group of patients (from 54.21 \pm 15.36 to $53.66 \pm$ $11.56 \%, p=0,677)$. There were no postoperative changes in other LV measurements including LVIDd, LVIDs, posterior and septal wall thickness, and LVmass index (Table 2).

When we divided our cohort according to the LVEF, significant improvement in LVEF was detected in the subgroup of patients with pre-operative LV dysfunction (from $40.05 \pm 8.65$ to $45.85 \pm 9.04 \%, p=$ 0.008 ), resulting in a mean change in LVEF of $5.80 \%$. On the other hand, there was a statistically significant decline in LVEF in the subgroup of patients with normal pre-operative LVEF (from $64.70 \pm 9.72$ to $59.44 \pm 9.75 \%, p=0.008$ ), resulting in a meaningful change in LVEF of $-5.26 \%$.

As for the other parameters of systolic function, statistically significant decrease in LVEDVI ( $p$ $=0.001)$, LVESVI $(p=0.0001)$, WMSI $(p=0.013)$ and LVmass index in male patients $(p=0.011)$ was shown only in patients with decreased LVEF after CABG (Table 2).

Table 2: Comparison of echocardiographic parameters of LV systolic function before and after CABG in patients divided according to the preoperative LEFT

\begin{tabular}{|c|c|c|c|c|c|c|}
\hline Parameters & All patients & $\mathrm{p}$ & $\begin{array}{c}\text { LVEF }>50 \% \\
N=27 \\
\end{array}$ & $\mathrm{p}$ & $\begin{array}{c}\text { LVEF } \leq 50 \% \\
\mathrm{~N}=20\end{array}$ & $\mathrm{p}$ \\
\hline $\begin{array}{l}\text { LVEF }(\%) \\
\text { Before CABG } \\
\text { After CABG }\end{array}$ & $\begin{array}{l}54.21 \pm 15.36 \\
53.66 \pm 11.56\end{array}$ & 0,677 & $\begin{array}{l}64.70 \pm 9.72 \\
59.44 \pm 9.75\end{array}$ & 0.008 & $\begin{array}{l}40.05 \pm 8.65 \\
45.85 \pm 9.04\end{array}$ & 0.008 \\
\hline LVIDd (mm) & & & & & & \\
\hline $\begin{array}{l}\text { Before CABG } \\
\text { Atter CABG } \\
\text { LVIDs (mm) }\end{array}$ & $\begin{array}{l}51.79 \pm 8.76 \\
51.83 \pm 8.34\end{array}$ & 0.981 & $\begin{array}{l}47.52 \pm 7.07 \\
48.07 \pm 6.26\end{array}$ & & $\begin{array}{l}57.55 \pm 7.51 \\
56.90 \pm 8.23\end{array}$ & \\
\hline $\begin{array}{l}\text { Before CABG } \\
\text { After CABG }\end{array}$ & $\begin{array}{l}33.96 \pm 10.52 \\
32.26 \pm 9.72\end{array}$ & 0.052 & $\begin{array}{l}28.44 \pm 7.50 \\
27.48 \pm 7.24\end{array}$ & 0.241 & $\begin{array}{l}41.40 \pm 9.45 \\
38.70 \pm 8.99\end{array}$ & 0.106 \\
\hline $\begin{array}{l}\text { IVSd }(\mathrm{mm}) \\
\text { Before CABG } \\
\text { After CABG }\end{array}$ & $\begin{array}{l}13.06 \pm 2.25 \\
12.34 \pm 2.66\end{array}$ & 0.037 & $\begin{array}{l}13.41 \pm 2.27 \\
12.74 \pm 2.55\end{array}$ & 0.111 & $\begin{array}{l}12.60 \pm 2.18 \\
11.80 \pm 2.78\end{array}$ & 0.175 \\
\hline $\begin{array}{l}P W d(\mathrm{~mm}) \\
\text { Before CABG } \\
\text { After CABG }\end{array}$ & $\begin{array}{l}11.21 \pm 2.04 \\
10.79 \pm 1.98\end{array}$ & 0.345 & $\begin{array}{l}11.56 \pm 1.98 \\
11.07 \pm 1.79\end{array}$ & 0.418 & $\begin{array}{l}10.75 \pm 2.07 \\
10.40 \pm 2.21\end{array}$ & 0.681 \\
\hline $\begin{array}{l}\text { LVEDVI (m/lm2) } \\
\text { Before CABG } \\
\text { After CABG }\end{array}$ & $\begin{array}{l}64.54 \pm 31.73 \\
54.41 \pm 22.22\end{array}$ & 0.001 & $\begin{array}{l}48.44 \pm 19.88 \\
43.65 \pm 14.62\end{array}$ & 0.107 & $\begin{array}{l}86.29 \pm 32.10 \\
68.94 \pm 22.71\end{array}$ & 0.001 \\
\hline $\begin{array}{l}\text { LVESVI ( } \mathrm{m} / \mathrm{m} 2) \\
\text { Before CABG } \\
\text { After CABG }\end{array}$ & $\begin{array}{l}33.89 \pm 27.19 \\
26.81 \pm 17.24\end{array}$ & 0.003 & $\begin{array}{c}17.52 \pm 10.60 \\
18.12 \pm 8.73\end{array}$ & 0.614 & $\begin{array}{l}55.99 \pm 27.24 \\
38.54 \pm 19.05\end{array}$ & 0.0001 \\
\hline $\begin{array}{l}\mathrm{SVI}(\mathrm{m} / \mathrm{m} 2) \\
\text { Before CABG } \\
\text { After CABG }\end{array}$ & $\begin{array}{r}38.08 \pm 9.99 \\
39.18 \pm 10.56\end{array}$ & 0.804 & $\begin{array}{l}38.97 \pm 10.03 \\
38.30 \pm 10.46\end{array}$ & 0.313 & $\begin{array}{l}36.89 \pm 10.07 \\
40.37 \pm 10.85\end{array}$ & 0.455 \\
\hline $\begin{array}{l}\text { MAPSEavarage (mm) } \\
\text { Before CABG } \\
\text { After CABG }\end{array}$ & $12.94 \pm 2.26$ & 0.001 & $13.81 \pm 2.32$ & 0.035 & $11.78 \pm 1.58$ & 0.008 \\
\hline $\begin{array}{l}\text { After CABG } \\
\text { s'TDI (cm/s) } \\
\text { Betore CABG }\end{array}$ & $14.08 \pm 2.08$ & & $14.98 \pm 1.98$ & 0.695 & $12.88 \pm 1.57$ & 0.281 \\
\hline $\begin{array}{l}\text { After CABG } \\
\text { WMSI }\end{array}$ & $6.12 \pm 1.21$ & 0.608 & $6.20 \pm 1.32$ & & $6.02 \pm 1.11$ & \\
\hline $\begin{array}{c}\text { Before CABG } \\
\text { After CABG } \\
\text { LVmass index (g/m2) }\end{array}$ & $\begin{array}{l}1.34 \pm 0.35 \\
1.23 \pm 0.23\end{array}$ & 0.016 & $\begin{array}{l}1.17 \pm 0.25 \\
1.12 \pm 0.14\end{array}$ & 0.615 & $\begin{array}{l}1.57 \pm 0.33 \\
1.37 \pm 0.25\end{array}$ & 0.013 \\
\hline & & & & & & \\
\hline $\begin{array}{l}\text { Before CABG } \\
\text { After CABG }\end{array}$ & $\begin{array}{l}143.43 \pm 39.26 \\
122.31 \pm 24.14\end{array}$ & 0.017 & $\begin{array}{l}129.04 \pm 33.39 \\
122.87 \pm 26.23\end{array}$ & 0.420 & $\begin{array}{l}158.67 \pm 40.14 \\
143.89 \pm 32.41\end{array}$ & 0.011 \\
\hline $\begin{array}{l}\text { Female } \\
\text { Before CABG } \\
\text { After CABG }\end{array}$ & $\begin{array}{l}133.08 \pm 30.85 \\
115.29 \pm 26.82 \\
\end{array}$ & 0.347 & $\begin{array}{l}113.84 \pm 20.52 \\
107.95 \pm 25.80 \\
\end{array}$ & 0.767 & $\begin{array}{l}147.72 \pm 15.15 \\
137.31 \pm 17.97 \\
\end{array}$ & 0.109 \\
\hline $\begin{array}{l}\text { CABG = coronary } \\
\text { end-diastolic volum } \\
\text { end-systolic volum } \\
\text { ventricular end-sys }\end{array}$ & 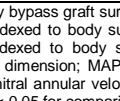 & & cindex IVSd & & $\begin{array}{l}\text { eess; LVEDVI = } \\
\text { ion; LVESVI = I }\end{array}$ & $\begin{array}{l}\text { tricular } \\
\text { tricular } \\
\text { chetet } \\
\text { ckness; } \\
\text { I = wall }\end{array}$ \\
\hline
\end{tabular}

The only parameter that significantly improved in both groups after CABG was MAPSE ( $p=0,035$, and $p=008$ in patients with preserved and reduced LVEF respectively). Except for MAPSE, none of the systolic echocardiographic parameters improved in the subgroup of patients with preserved LVEF (Table 2).

\section{Parameters related to LVEF change post CABG surgery}

In our study, out of 47 patients, 4 patients (8.5\%) had unchanged LVEF (+ / -5\%) after successful CABG operation, 25 patients $(53.2 \%)$ had increased LVEF (> 5\%) and 18 patients $(38.3 \%)$ had decreased in the postoperative LVEF (> 5\%). Comparison of the three groups (Table 3) showed an only significant difference between patients with improved and decreased postoperative LVEF. Thus, patients with improved postoperative LVEF had significantly lower baseline LVEF $(p=0.0001)$, higher LVESVI (0.009) and higher WMSI $(p=0.006)$ vs patients with worsened postoperative LEFT.

Table 3: Baseline echocardiographic parameters of all patients about perioperative change in left ventricular ejection fraction

\begin{tabular}{lcccc}
\hline Parameter & $\begin{array}{c}\text { Unchanged EF } \\
\mathrm{N}=4\end{array}$ & $\begin{array}{c}\text { Improved EF } \\
\mathrm{N}=25\end{array}$ & $\begin{array}{c}\text { Worsened EF } \\
\mathrm{N}=18\end{array}$ & $\mathrm{p}$ \\
\hline LVIDd $(\mathrm{mm})$ & $48.0 \pm 3.9$ & $53.7 \pm 9.3$ & $49.8 \pm 8.3$ & 0.243 \\
LVIDs (mm) & $29.0 \pm 4.2$ & $37.1 \pm 11.6$ & $30.7 \pm 8.6$ & 0.089 \\
IVSd (mm) & $13.2 \pm 2.9$ & $12.9 \pm 2.4$ & $13.1 \pm 1.8$ & 0.945 \\
PWd (mm) & $10.2 \pm 1.5$ & $10.8 \pm 2.3$ & $11.9 \pm 1.5$ & 0.173 \\
LVEDVI (ml/m2) & $64.1 \pm 34.1$ & $74.0 \pm 33.6$ & $51.4 \pm 24.7$ & 0.069 \\
& & & & 0.009 \\
LVESVI (ml/m2) & $25.7 \pm 11.3$ & $44.9 \pm 30.9$ & $20.3 \pm 15.5$ & $\begin{array}{c}\text { Improved vs. } \\
\text { Worsened }\end{array}$ \\
& & & & 0.0001 \\
LVEF (\%) & $56.7 \pm 5.1$ & $46.6 \pm 14.9$ & $64.1 \pm 11.2$ & Improved vs. \\
& & & & Worsened \\
SVI (ml/m2) & $36.5 \pm 6.0$ & $37.9 \pm 10.2$ & $38.6 \pm 10.7$ & 0.930 \\
CI (L/min/m2) & $2.7 \pm 0.8$ & $2.5 \pm 0.7$ & $2.6 \pm 0.7$ & 0.888 \\
MAPSEavarage (mm) & $14.1 \pm 2.6$ & $12.4 \pm 1.9$ & $13.2 \pm 2.5$ & 0.277 \\
s'TDI (cm/s) & $5.4 \pm 0.9$ & $5.9 \pm 1.5$ & $6.2 \pm 1.4$ & 0.544 \\
& & & & 0.006 \\
WMSI & $1.3 \pm 0.2$ & $1.4 \pm 0.4$ & $1.3 \pm 0.3$ & Improved vs. \\
& & & & Worsened \\
\hline CABG $=$ corm & & & &
\end{tabular}

CABG = coronary artery bypass graft surgery; $\mathrm{Cl}$ = cardiac index; IVSd = septal wall thickness; LVEDVI = left ventricular end-diastolic volume indexed to body surface area; LEFT = left ventricular ejection fraction; LVESVI = left ventricular end-systolic volume indexed to body surface area; LVIDd = left ventricular end-diastolic dimension; LVIDs = left ventricular end-systolic dimension; MAPSE = mitral annular plane systolic excursion; PW = posterior wall thickness; s'TDI = peak systolic mitral annular velocity by TDI; SVI = systolic volume indexed to body surface area; $\mathrm{WMSI}=$ wall motion score index; ${ }^{*} \mathrm{p}<0.05$ for volume indexed to body surtac
comparison between groups.

Postoperative improvement of LVEF was correlated with stabile angina, lack of preoperative myocardial infarction and smoking, higher baseline WMSI, higher LV internal diameters and indexed volumes in diastole and systole and lower baseline LVEF (Table 4).

Table 4: Correlation between the change of LVEF and preoperative parameters

\begin{tabular}{lc}
\hline Parameters & $\Delta$ LVEF \\
\hline Angina (\%) & $\mathrm{R}=0.386 ; \mathrm{p}=0.007$ \\
Previous MI (\%) & $\mathrm{R}=-0.288 ; \mathrm{p}=0.049$ \\
Smoking (\%) & $\mathrm{R}=-0.319 ; \mathrm{p}=0.029$ \\
LVIDd (mm) & $\mathrm{R}=-0.294 ; \mathrm{p}=0.045$ \\
LVIDs (mm) & $\mathrm{R}=-0.404 ; \mathrm{p}=0.005$ \\
LVEDVI (ml/m2) & $\mathrm{R}=-0.467 ; \mathrm{p}=0.001$ \\
LVESVI (ml/m2) & $\mathrm{R}=-0.557 ; \mathrm{p}=0.0001$ \\
LVEF & $\mathrm{R}=0.652 ; \mathrm{p}=0.0001$ \\
WMSI & $\mathrm{R}=-0.480 ; \mathrm{p}=0.001$ \\
\hline
\end{tabular}


To determine the independent predictors of improvement of LVEF after CABG, we performed multiple stepwise linear regression analysis with covariates that showed a significant relation to it. The results demonstrated that the value of baseline LVEF appeared as an independent predictor of improved LVEF after CABG (Table 5, Figure 1).

Table 5: Stepwise regression analysis of LVEF after CABG as the dependent variable and clinical and echocardiographic parameters as independent variables in cases for which LVEF improved

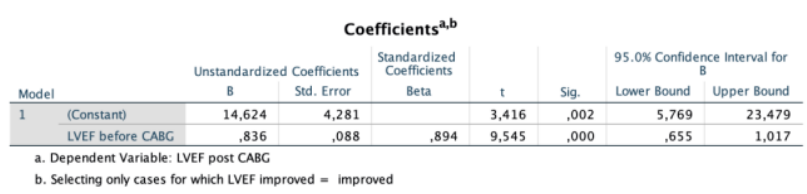

Thus, for every $1 \%$ absolute decrease in preoperative LVEF, there is postoperative improvement of LVEF of $0,836 \%(95 \% \mathrm{Cl} 0.655-1.017 ; p=0.0001)$.

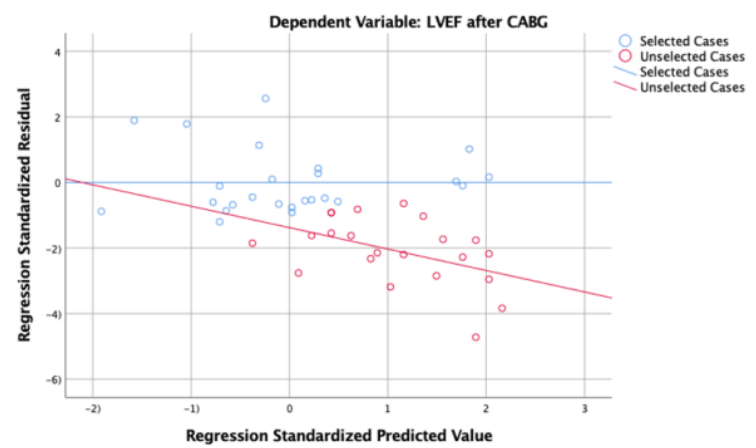

Figure 1: Graphical presentation of regression standardised predicted value for $\angle V E F$ after CABG as the dependent variable in cases for which LVEF improved

\section{Discussion}

CABG surgery can improve the myocardial blood supply in the hibernating regions of the heart. This results in increased contractility and better performance of the myocardium [11], [12]. The 2D biplane echocardiography is a widely used method to obtain pre and postoperative systolic parameters of the right and left ventricle in patients undergoing CABG surgery.

In this study, the parameters of LV ejection fraction, LV internal dimensions and LV indexed volumes in systole and diastole, cardiac index, mitral annular plane systolic excursion, wall motion score index and LV mass index obtained with conventional $2 \mathrm{D}$ echocardiography were used to assess the global systolic function in patients with CAD undergoing CABG.
We showed deterioration in LVEF after CABG in patients with normal baseline LVEF. Except for MAPSE, other systolic parameters did not change significantly even after successful CABG treatment in patients with preserved baseline LVEF. On the other hand, an improvement in LV systolic function was observed in patients with decreased pre-operative LVEF. There were significant improvement in LVEF, LV systolic and diastolic indexed volumes, WMSI and LV mass index in this subgroup of patients.

Prior studies have similarly found an improvement in LVEF and other systolic parameters in patients with pre-operative LV systolic dysfunction. In the largest prospective, randomised, controlled trial, the STICH trial, Michler et al., [13] in a post hoc subgroup analysis showed a significant improvement in LV size and function in the subgroup of patients with higher baseline LV end-systolic dimensions. Our study also showed improvement in LVEF in the subgroup of patients with preoperative LV systolic dysfunction and higher baseline internal diameters as well as indexed volumes of LV in diastole and systole.

While many studies evaluate changes of perioperative systolic parameters in patients with reduced LVEF, only a few studies examine changes in LV systolic function in patients with preserved baseline LVEF. In a small prospective study, Diller et al. demonstrated improvement in LV diastolic function and did not find a significant reduction in LVEF immediately after CABG [14]. In the largest study to assess pre and post-operative echocardiograms in a population including both normal and reduced preoperative LV function, Koene et al., [8] showed a decrease in LVEF with CABG in patients with normal baseline LV systolic function. In this study, the magnitude of decrease in LVEF was $3 \%$ mean and ranged from $-33 \%$ to $15 \%$. Our study is in agreement with these findings demonstrating a decrease in LVEF in patients with preserved baseline LVEF resulting in a mean decrease in LVEF of $5.26 \%$. This postoperative decrease in LVEF might result from myocardial stunning [15], reperfusion injury [16] and early postoperative graft failure [17].

In our study, a total of 18 patients $(38.3 \%)$ had decreased in the postoperative LVEF (> 5\%). This suggests that $C A B G$ itself contributes to postoperative myocardial dysfunction. Although these patients were angina free 4-6 mounts after CABG, the relative decline in LVEF suggests that myocardial recovery might take longer time. We strongly believe that these results are worthy of further investigation to understand the effect of CABG on myocardial function. Another issue that should be investigated is whether the lack of improvement of LVEF post-CABG portends a worse outcome.

The major limitations in our study are that we used only conventional 2-D echocardiography imaging to assess pre and postoperative systolic LV function. Other technologies such as magnetic resonance 
imaging, positron emission tomography and speckle tracking imaging might have yielded other results, but 2-D echocardiography is a widely used method for quantifying perioperative LV function. This study has the advantage of being prospective and all consecutive patients that met inclusion criteria were enrolled in the study but we believe that their number is too small and is thus hypothesis-generating rather than definitive. Another disadvantage is that paired echocardiograms were done a maximum of 6 months after surgery, time that might be too short for complete myocardial recovery after surgery. In our study, all patients were done on the pump with crystalloid cardioplegia and this might affect postoperative LV function in a certain percentage of patients.

In conclusion, our study showed that LVEF, internal baseline diameters and indexed volumes of LV in diastole and systole are important determinants of postoperative change in LVEF. In patients with the preoperative depressed myocardial function, we should expect improvement in systolic function, whereas in patients with preserved myocardial function, decline in postoperative LVEF should be anticipated, despite successful CABG. The present study suggests further investigations in order to understand the effect of CABG on myocardial function.

\section{References}

1. Win Decker S, Strobeck S, Stefani GG, et al. Revascularization versus medical treatment in patients with stable coronary artery disease: Network meta-analysis. BMJ. 2014; 348:g3859.

2. Yusuf $S$, Zucker D, Peduzzi $P$, et al. Effect of coronary artery bypass graft surgery on survival: Overview of 10 -year results from randomized trials by the Coronary Artery Bypass Graft Surgery Trialists Collaboration. Lancet. 1994; 344:563-70. https://doi.org/10.1016/S0140-6736(94)91963-1

3. Velazquez EJ, Lee KL, Jones RH, et al. STICHES Investigators. Coronary-artery bypass surgery in patients with ischemic cardiomyopathy. N Engl J Med. 2016; 374:1511-20. https://doi.org/10.1056/NEJMoa1602001 PMid:27040723 PMCid:PMC4938005

4. Neumann FJ, Sousa-Uva M, Ahlsson A, et al. ESC Scientific Document Group. 2018 ESC/EACTS Guidelines on myocardial revascularization. Eur Heart J. 2018; 00:1-96. https://doi.org/10.5603/KP.2018.0228 PMid:30566213

5. Anavekar NS, Chareonthaitawee P, Narula J, Gersh BJ. Revascularization in Patients With Severe Left Ventricular Dysfunction: Is the Assessment of Viability Still Viable? J Am Coll Cardiol. 2016; 67:2874-87. https://doi.org/10.1016/j.jacc.2016.03.571 PMid:27311527

6. Rubenson DS, Tucker CR, London E, et al. Two-dimensional echocardiographic analysis of segmental left ventricular wall motion before and after coronary bypass surgery. Circulation. 1982; 66:1025-33. https://doi.org/10.1161/01.CIR.66.5.1025 PMid:6982113

7. Elefteriades JA, Tolls G, Levi E, Mills LK, Zaret BL. Coronary artery bypass grafting in severe left ventricular dysfunction: excellent survival with improved ejection fraction and functional state. J Am Cell Cardiol. 1993; 22:1411-7. https://doi.org/10.1016/0735-1097(93)90551-B

8. Koene RJ, Kealhofer JV, Adabag S, et al. Effect of coronary artery bypass graft surgery on left ventricular systolic function. $\mathrm{J}$ Thorac Dis. 2017; 9:262-70. https://doi.org/10.21037/jtd.2017.02.09 PMid:28275473 PMCid:PMC5334093

9. Yin ZY1, Li XF, Tu YF, et al. Speckle-tracking imaging to monitor myocardial function after coronary artery bypass graft surgery. $J$ Ultrasound Med. 2013; 32:1951-6.

https://doi.org/10.7863/ultra.32.11.1951 PMid:24154899

10. Lang RM, Badano LP, Mor-Avi V, et al. Recommendations for cardiac chamber quantification by echocardiography in adults: An update from the American Society of Echocardiography and the

European Association of Cardiovascular Imaging. Eur Heart J Cardiovasc Imaging. 2015; 16:233-71.

https://doi.org/10.1093/ehjci/jev014 PMid:25712077

11. Bax JJ, Van der Wall EE. Assessment of myocardial viability: guide to prognosis and clinical management. Eur Heart J. 2000;

21:961-963. https://doi.org/10.1053/euhj.2000.2110

PMid:10901505

12. Bair TL, Muhlestein JB, May HT, et al. Surgical revascularization is associated with improved long-term outcomes compared with percutaneous stenting in most subgroups of patients with multivessel coronary artery disease: results from the Intermountain Heart Registry. Circulation. 2007; 116(11):I226-I231 https://doi.org/10.1161/CIRCULATIONAHA.106.681346 PMid:17846308

13. Michler RE, Rouleau JL, Al-Khalidi HR, et al. Insights from the STICH trial: change in left ventricular size after coronary artery bypass grafting with and without surgical ventricular reconstruction. J Thorac Cardiovasc Surg. 2013; 146:1139-45.e6. https://doi.org/10.1016/j.jtcvs.2012.09.007 PMid:23111018 PMCid:PMC3810307

14. Diller GP, Wasan BS, Kyriacou A, et al. Effect of coronary artery bypass surgery on myocardial function as assessed by tissue Doppler echocardiography. Eur J Cardiothorac Surg. 2008; 34:995-9. https://doi.org/10.1016/j.ejcts.2008.08.008 PMid:18829341

15. Leung JM. Clinical evidence of myocardial stunning in patients undergoing CABG surgery. J Card Surg. 1993; 8:220-3. https://doi.org/10.1111/j.1540-8191.1993.tb01310.x PMid:8461506

16. Lin PJ, Chang $\mathrm{CH}$, Lee YS, et al. Acute endothelial reperfusion injury after coronary artery bypass grafting. Ann Thorac Surg. 1994; 58:782-8. https://doi.org/10.1016/0003-4975(94)90749-8

17. Oshima $\mathrm{H}$, Tokuda $\mathrm{Y}$, Araki $\mathrm{Y}$, et al. Predictors of early graft failure after coronary artery bypass grafting for chronic total occlusion. Interact Cardiovasc Thorac Surg. 2016; 23:142-9. https://doi.org/10.1093/icvts/ivw084 PMid:27030683 PMCid:PMC4986749 